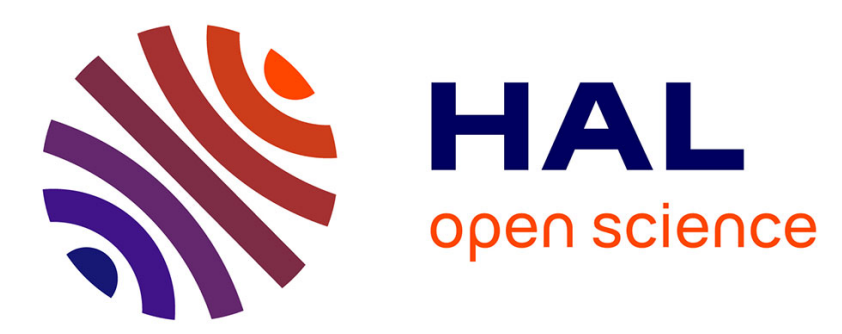

\title{
Compact Flat Dipole Rectenna for Energy Harvesting or Wireless Power Transmission Applications
}

Abderrahim Okba, Alexandru Takacs, Hervé Aubert

\section{To cite this version:}

Abderrahim Okba, Alexandru Takacs, Hervé Aubert. Compact Flat Dipole Rectenna for Energy Harvesting or Wireless Power Transmission Applications. IEEE International Symposium on Antennas and Propagation (APS), Jul 2018, Boston, United States. 10.1109/APUSNCURSINRSM.2018.8608906 . hal-02066068

\section{HAL Id: hal-02066068 https://hal.laas.fr/hal-02066068}

Submitted on 13 Mar 2019

HAL is a multi-disciplinary open access archive for the deposit and dissemination of scientific research documents, whether they are published or not. The documents may come from teaching and research institutions in France or abroad, or from public or private research centers.
L'archive ouverte pluridisciplinaire HAL, est destinée au dépôt et à la diffusion de documents scientifiques de niveau recherche, publiés ou non, émanant des établissements d'enseignement et de recherche français ou étrangers, des laboratoires publics ou privés. 


\title{
Compact Flat Dipole Rectenna for Energy Harvesting or Wireless Power Transmission Applications
}

\author{
Abderrahim OKBA, Alexandru TAKACS, Hervé AUBERT \\ LAAS-CNRS, UPS, INPT \\ Toulouse, France \\ aokba@laas.fr, atakacs@laas.fr, aubert@laas.fr
}

\begin{abstract}
This paper addresses the design and the characterization of a compact $(2.3 \mathrm{~cm} \times 3.4 \mathrm{~cm})$ flat dipole antenna surrounded by a rectangular ring. Due to its wide frequency bandwidth, this antenna covers the UMTS, LTE 4G, WiFi and WiMAX (IEEE 802.16e) bands and can be advantageously used for RF Energy Harvesting or Wireless Power Transmission applications. A compact rectenna using the proposed antenna was manufactured and characterized. It allows reaching a RF-DC conversion efficiency of $38.6 \%$ for an E-field of $7 \mathrm{~V} / \mathrm{m}$ with a $1.5 \mathrm{k} \Omega$ load.
\end{abstract}

Keywords - Compact antenna, flat dipole, rectenna, energy harvesting, wireless power transmission

\section{INTRODUCTION}

Nowadays the radiofrequency (RF) Energy Harvesting (EH) and alternatively, the Wireless Power Transmission (WPT) techniques, become a credible and realistic solution to implement the next generation of the self-powered/batteryless devices required by the massive implementation of the Internet of Things (IoT) applications. The implementation of RF EH and/or WPT requires the use of a rectenna to power the selfpowered/batteryless IoT devices. From an industrial point of view, a successful rectenna design for IoT applications should be at least compact, low-profile and low-cost. The size of the rectenna module is mainly given by the dimensions of the receiving antenna and consequently, there is an increasing interest in the scientific and industrial communities to design compact antennas/rectennas for RF EH and WPT applications [1].

This paper addresses the design of a compact antenna for EH applications in the UMTS, LTE 4G, WiFi and WiMAX (IEEE 802.16e) bands, or for the WPT applications in IMS 2.45GHz band.

\section{Flat Dipole ANTENNA}

The half wavelength dipole antennas were used in the past for rectenna design operating in the targeted frequency band. The main drawback of such antennas is related to their narrowband behavior. One solution to increase the bandwidth and decreasing the overall length of the dipole antennas is to use a flat dipole (FD) topology [2]. The size of the FD can be also compacted by surrounding this antenna by a properly designed rectangular ring, as illustrated in the Fig. 1(e). In order to characterize such Surrounding Ring Flat Dipole (SRFD) antenna, a tapered transition from the differential (symmetric) feed of the FD and a coaxial connector was designed having in mind two antagonistic criteria: (i) providing a good impedance matching in a bandwidth as large as possible and, (ii) minimizing the length of the transition. The current density distribution on a (printed) half wavelength dipole and flat dipole are displayed respectively on Fig. 1 (a) and (b). On the surface of the FD antenna the current flows on different paths (see, e.g., the paths Js1 and Js2 in Fig. 1(b)). The bandwidth is increased thanks to the longest paths, while the physical length of the FD antenna is smaller than one of the half-wavelength dipole.

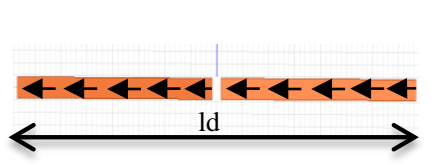

a)
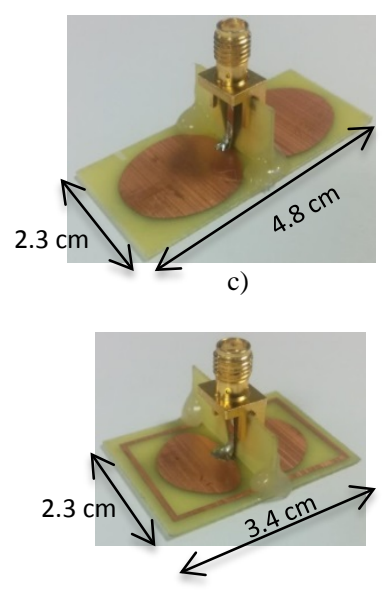

e)

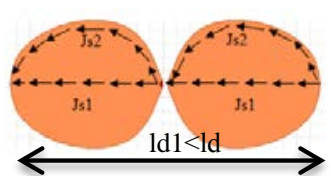

b)

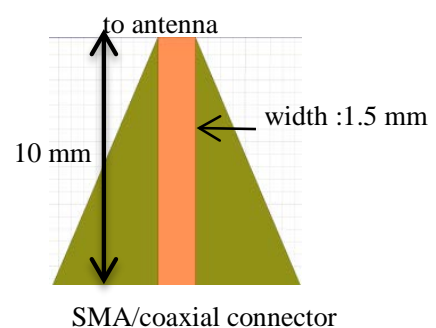

d)

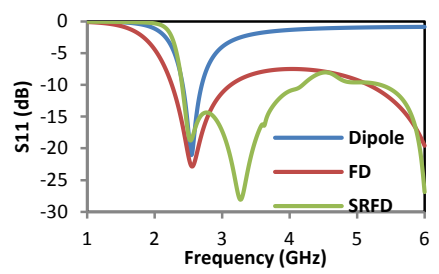

f)
Fig. 1. Sketch of the current density distribution on the surface of : (a) the printed half-wavelength dipole and (b) the FD antenna; (c) Photo of the manufactured FD antenna including feeding transition; (d) dimensions of the tapered transition; (e) Photo of the manufactured SRFD antenna and (f) the reflexion coefficient (S11) at the input of the half wavelength dipole (blue curve), FD (red curve) and SRFD (green curve) versus frequency (simulation results obtained from HFSS software)

The antennas were manufactured on low-cost FR4 substrate (thickness: $0.8 \mathrm{~mm}$, dielectric constant: 4.4 and dielectric loss tangent: 0.02). A FD antenna (denoted here by FD1) was first designed with a lowest operating frequency around $3.9 \mathrm{GHz}$. Next, a metallic ring was used to surround the antenna in order 
to lower the operation frequency. The ring perimeter $(11.4 \mathrm{~cm})$ and the FD1-to-ring distance were adjusted for minimizing the lowest operating frequency. Fig. 2 depicts the resulting reflection coefficients for the optimized SRFD antenna.

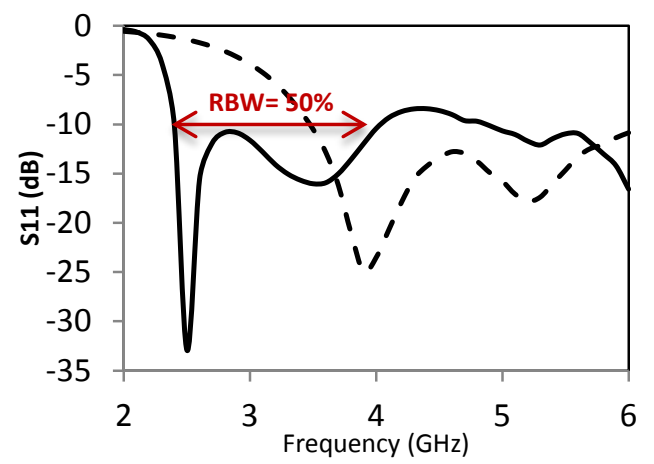

Fig. 2. Simulated (HFSS software) reflection coefficient at the input of the FD1 (dotted line) and SRFD (continous line) antennas

The radiation pattern of the manufactured SRFD antenna was measured in an anechoic chamber (see Fig. 3). A metallic plate $\left(10 \times 10 \mathrm{~cm}^{2}\right)$ is placed at $3 \mathrm{~cm}$ behind the antenna in order to increase the gain and reduce the impact on the measurement results of the mechanical (metallic) system used for supporting the antenna. The maximum gain of $6.3 \mathrm{dBi}$ is measured at $2.4 \mathrm{GHz}$.

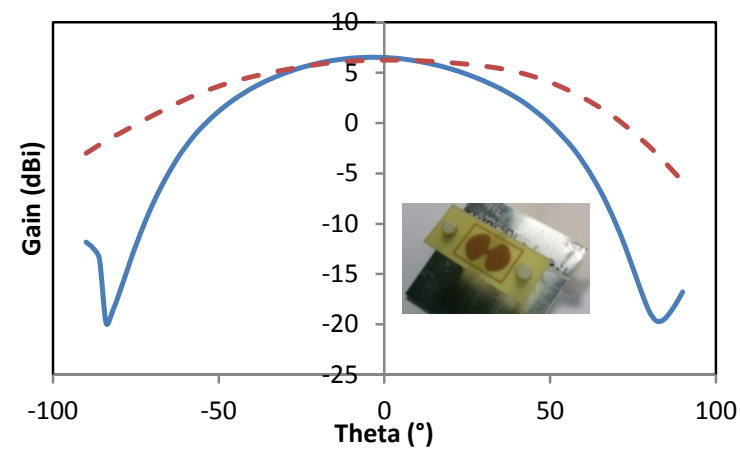

Fig. 3. Measured radiation pattern (gain) for SRFD for two vertical planes ( $\mathrm{XoZ}-$ phi $=0$ : blue continous line and $\mathrm{YoZ}-\mathrm{phi}=90^{\circ}$ : red dotted line) as function of theta angle (a standard spherical coordinate system with $\mathrm{Oz}$ axis perpendincular to the antenna surface was used). The inset shows a photo of the manufactured SRFD antenna with its metallic plate.

The SRFD antenna is now connected to a rectifier previously developed for ISM $2.45 \mathrm{GHz}$ applications. The rectifier uses a (serially connected) HSMS2850 Schottky diode and a matching network composed of a short-circuited stub and an inductance of $5.6 \mathrm{nH}$. A $10 \mathrm{pF}$ shunt capacitor is used as a DC-pass filter and the optimal load is about $1.5 \mathrm{k} \Omega$. The rectenna measurements are performed in an anechoic chamber using a standard horn antenna connected to a RF generator in order to create the incident power density on the rectenna under test. As shown in Fig.4, the SRFD rectenna allows obtaining a DC power higher than $100 \mu \mathrm{W}$ from an E-field higher than $4 \mathrm{~V} / \mathrm{m}$. The conversion efficiency (that is, the ratio between the measured DC power and the RF power derived from the antenna effective surface and the incident EM power density [1]) reaches $38.6 \%$ at $2.3 \mathrm{GHz}$ for electric field amplitude ranging from $7 \mathrm{~V} / \mathrm{m}$ to $11 \mathrm{~V} / \mathrm{m}$.

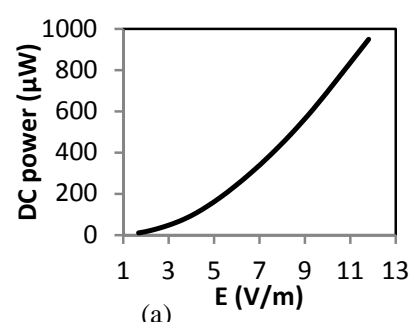

(a)

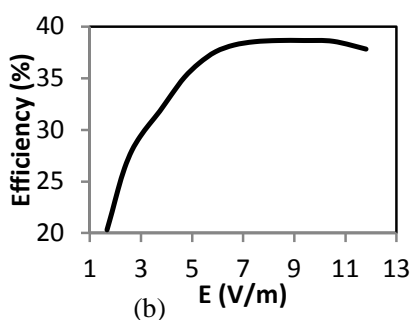

(b)
Fig. 4. (a) The measured harvested DC power and (b) SRFD rectenna efficiency as a function of the incident electric field amplitude at $2.3 \mathrm{GHz}$ (load impedance $=1.5 \mathrm{k} \Omega$ ).

In Table I, the rectenna performances are compared with state-of-art. The proposed design is more compact and operates efficiently for lowest power densities. A wideband/multiband rectifier is under design in order to fully take advantage of the wideband behaviour of SRFD antenna and more results will be presented at conference.

TABLE I. BENCHMARK RESULTS

\begin{tabular}{|c|c|c|c|c|c|}
\hline Ref & $\begin{array}{c}\text { Operating } \\
\text { frequency } \\
\mathrm{f}_{0}(\mathrm{GHz})\end{array}$ & $\begin{array}{c}\text { Power } \\
\text { density } \\
\left(\mu \mathrm{W} / \mathrm{cm}^{2}\right) \text { or } \\
\text { received RF } \\
\text { power }(\mathrm{dBm})\end{array}$ & $\begin{array}{c}\text { Harves } \\
\text { ted DC } \\
\text { power } \\
(\mathrm{mW})\end{array}$ & $\begin{array}{c}\text { Rectenna } \\
\text { efficiency } \\
(\%)\end{array}$ & $\begin{array}{c}\text { Antenna } \\
\text { Surface } \\
\left(\lambda_{0} \text { is the }\right. \\
\text { wavelength } \\
\left.\text { at } \mathrm{f}_{0}\right)\end{array}$ \\
\hline$[3]$ & 2.45 & $525 \mu \mathrm{W} / \mathrm{cm}^{2}$ & 4.97 & 63 & $\begin{array}{c}10 \times 11 \mathrm{~cm}^{2} \\
\left(0.73^{*} \lambda_{0}{ }^{2}\right)\end{array}$ \\
\hline$[4]$ & 2.45 & $13 \mathrm{dBm}$ & --- & 72.5 & $\begin{array}{c}13.5 \times 9,3 \\
\mathrm{~cm}^{2} \\
\left(0.83^{*} \lambda_{0}{ }^{2}\right)\end{array}$ \\
\hline$[5]$ & 2.4 & $22 \mathrm{dBm}$ & 130 & 82.3 & $\begin{array}{c}10 \times 10 \mathrm{~cm}^{2} \\
\left(0.64 * \lambda_{0}^{2}\right)\end{array}$ \\
\hline $\begin{array}{c}\text { This } \\
\text { work }\end{array}$ & 2.3 & $\begin{array}{c}23 \mu \mathrm{W} / \mathrm{cm} \\
\text { or } 2 \mathrm{dBm}\end{array}$ & 0.95 & 38.6 & $\begin{array}{c}3.4 \times 2.3 \mathrm{~cm}^{2} \\
\left(0.046^{*} \lambda_{0}{ }^{2}\right)\end{array}$ \\
\hline
\end{tabular}

\section{CONCLUSION}

A compact flat dipole antenna surrounded by a rectangular ring for energy harvesting/wireless power transmission applications was designed, fabricated and characterized. This antenna exhibits a wideband behavior (relative bandwidth of $50 \%$ ). A rectenna was developed by connecting the antenna to a previously designed (narrowband) rectifier. A maximum efficiency of $38.6 \%$ was measured for an RF power density of $23 \mu \mathrm{W} / \mathrm{cm}^{2}$ at $2.3 \mathrm{GHz}$.

\section{REFERENCES}

[1] Z. Popovic; E.A. Falkenstein, D. Costinett, R. Zane, Low-Power FarField Wireless Powering for Wireless Sensors, Proceedings of the IEEE, Vol. 101, No. 6, pp.1397 -1407, June 2013.

[2] V. Kuhn, C. Lahuec, F. Seguin, and C. Person, "A Multi-Band Stacked RF Energy Harvester With RF-to-DC Efficiency Up to 84\%,” IEEE Trans. Microw. Theory Tech., vol. 63, no. 5, pp. 1768-1778, May 2015.

[3] Z, Harouni, L, Cirio, L, Osman, A, Gharsallah, and O, Picon, "A Dual Circularly Polarized 2,45-GHz Rectenna for Wireless Power Transmission,” IEEE Antennas Wirel, Propag, Lett,, vol, 10, pp, 306309, 2011

[4] N. Mei-Juan, “A compact $2.45 \mathrm{GHz}$ Broadband Rectenna Using Grounded Coplanar Waveguide.” IEEE Antennas and Wireless Propagation Letters, vol. 14, pp. 986 - 989, January 2015.

[5] J. H. Chou, D. B. Lin, K. L. Weng, and H. J. Li, "All Polarization Receiving Rectenna With Harmonic Rejection Property for Wireless Power Transmission,” IEEE Trans. Antennas Propag., vol. 62, no. 10, pp. 5242-5249, Oct. 2014. 